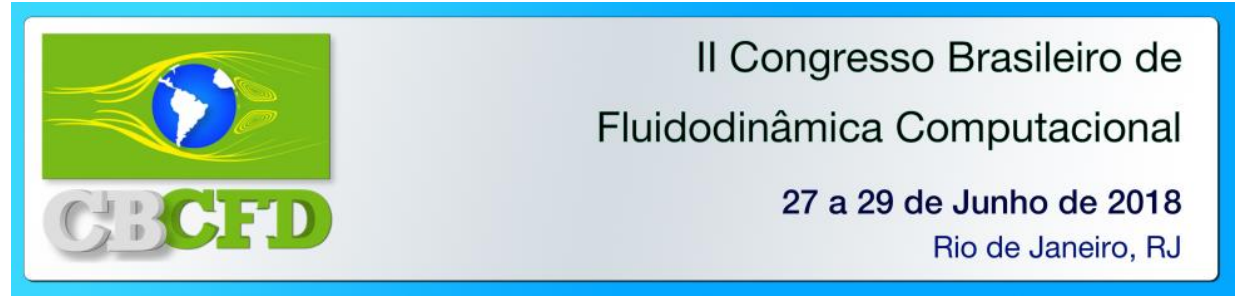

\title{
SIMULAÇÃO COMPUTACIONAL DO ESCOAMENTO PARA PROPOSTA DE NOVO EQUIPAMENTO DE COLETA DE MATERIAIS PARTICULADOS
}

\author{
P. V. F. MOREIRA ${ }^{1}$, C. E. S. BONFIM ${ }^{2}$, W. M. POUBEL ${ }^{1}$ \\ ${ }^{1}$ Universidade Federal do Espírito Santo, Departamento de Engenharia Química \\ ${ }^{2}$ Instituto de Defesa Química, Biológica, Radiológica e Nuclear, Seção de Defesa Química \\ E-mail para contato: willian.poubel@ufes.br
}

\begin{abstract}
RESUMO - Temas ligados ao meio ambiente vêm sendo cada vez mais recorrentes nos noticiários mundiais. Os assuntos 'efeito estufa', 'aquecimento global', 'camada de ozônio', 'poluição atmosférica', dentre outros, estão se tornando comum no nosso meio. Presente desde os conteúdos programáticos das séries iniciais até as conversas cotidianas e pesquisas mais elaboradas, é um assunto que está em evidência em todos os meios de comunicação. O trabalho simula um aparelho proposto inédito para diminuir a incidência de material particulado na atmosfera, através do software ANSYS® 17.0. Foi obtido resultados dos perfis de velocidade do equipamento, sendo possível futura análise e estudo de novas simulações com variadas cargas de poluentes e aplicações em ambientes industriais. Os dados do presente trabalho justificam próximas etapas do estudo de redução de lançamentos de poluentes particulados para a atmosfera.
\end{abstract}

\section{INTRODUÇÃO}

A população mundial apresenta um crescimento exponencial que pode gerar diversos fatores danosos ao meio ambiente. Quanto maior a população, maior a demanda e o uso dos recursos ambientais, acarretando diversos prejuízos ao planeta. Dentre os diversos tipos de poluição se destaca a poluição atmosférica e sua relação entre o crescimento populacional.

Segundo Thurston (2008), a degradação da qualidade do ar é um desafio mundial da humanidade, pois traz diversos danos à saúde da população e por ser tão facilmente difundido e emitido por diversas fontes distintas, não sendo tão visível pela dinâmica da atmosfera em dispersar os poluentes, diferente dos outros tipos de poluição.

De acordo com a Organização Mundial da Saúde, mais de $90 \%$ da população mundial respira ar contaminado (níveis de poluentes ultrapassam os limites predeterminados), fato este que causa milhões de mortes todos os anos, além de aumentar o número de pessoas desenvolvendo problemas respiratórios ou agravando problemas preexistentes (OMS, 2016).

Paoli (2006) evidencia que o processo de dispersão pode ser resumido em três fases, sendo que a primeira fase é a influência da chaminé, devido ao efeito aerodinâmico criado por ela, afetando a pluma de poluentes lançada na atmosfera. Portanto, fica evidenciado que o estudo e 


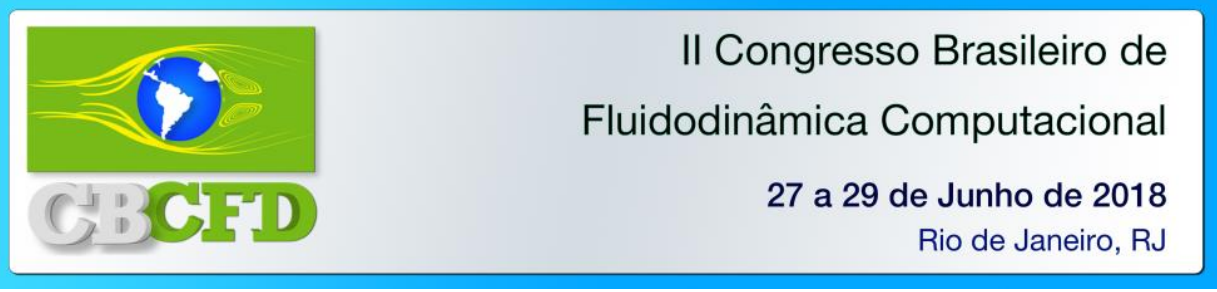

busca por melhorias nas chaminés são fatores importantes para a pesquisa científica, a fim de buscar os melhores métodos para a utilização das chaminés e os melhores modelos para uso.

Pfluck (2010) salienta que a utilização de técnicas computacionais (CFD) no estudo de dispersões e escoamentos de poluentes é bastante eficaz, podendo construir e obter resultados de mesma característica de experimentos laboratoriais, porém com o custo muito mais baixo do que o realizado em escalas laboratoriais, por não demandar de nenhum equipamento e reagente utilizado em laboratório.

\section{OBJETIVO}

O objetivo do presente estudo é analisar o escoamento e o perfil de velocidade no interior de um equipamento com desenho inédito que será destinado a separação de partículas.

\section{MATERIAIS E MÉTODOS}

A geometria a ser acoplada na saída da chaminé foi construída no software ANSYS Design Modeler, para realizar as simulações iniciais de escoamento com dimensões máximas de $1,5 \mathrm{~m}$ x $1,5 \mathrm{~m}$ x 1,0m. A construção da malha foi realizada através do software Meshing e a malha foi tratada utilizando o método de convergência de malhas, visando encontrar uma malha eficiente, que demandasse menos tempo de processamento no programa e com boa aproximação dos resultados, se comparada a outras malhas mais refinadas.

Para a escolha da malha, fez-se o teste de convergência de malha com 4 malhas diferentes, como pode ser observado na Figura 1.

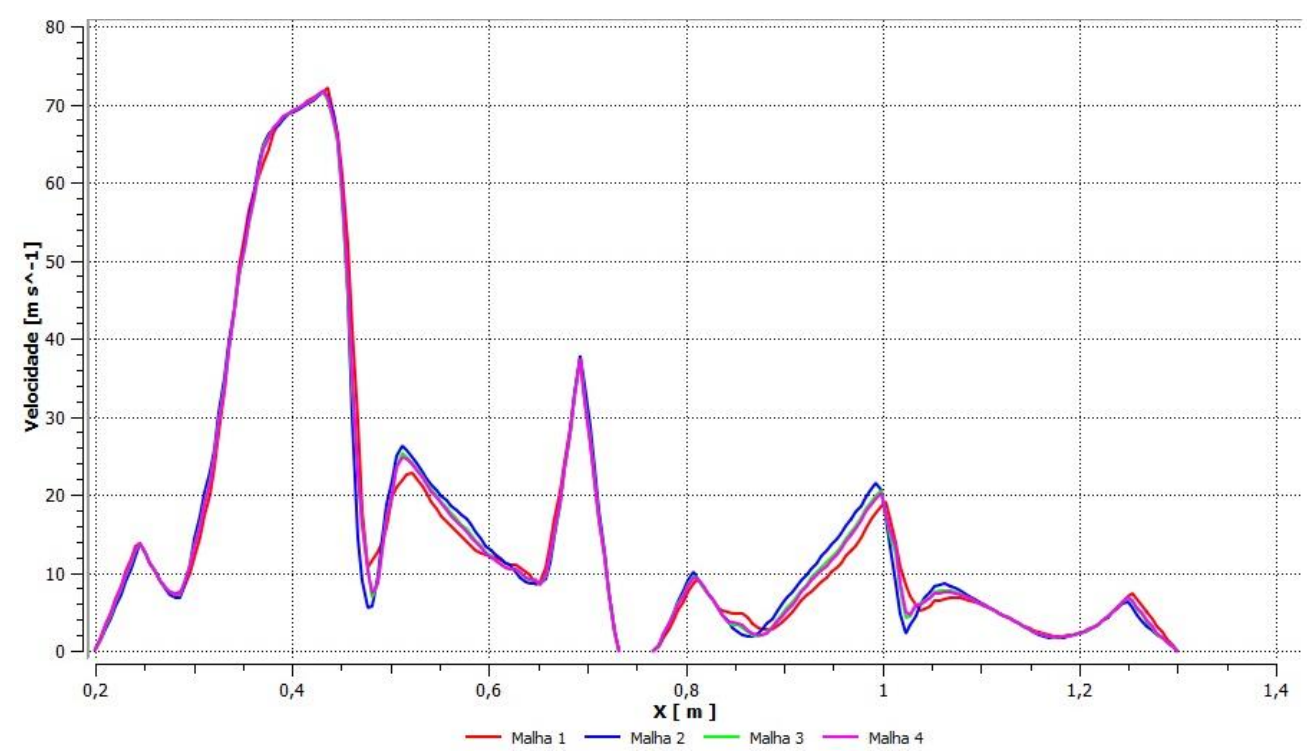

Figura 1 - Perfis de velocidade no interior do equipamento referentes a 4 malhas distintas

Como as malhas 3 e 4 apresentaram respostas semelhantes, utilizou-se no processo a malha 3, pois esta demandou menos tempo de processamento e resposta bem aproximada da resposta da malha 4. A malha utilizada possui estrutura tetraédrica, 59814 nós e 299838 elementos, e pode ser vista na Figura 2. Mais detalhes sobre convergência de malha podem ser encontrados em Pfluck (2010). 

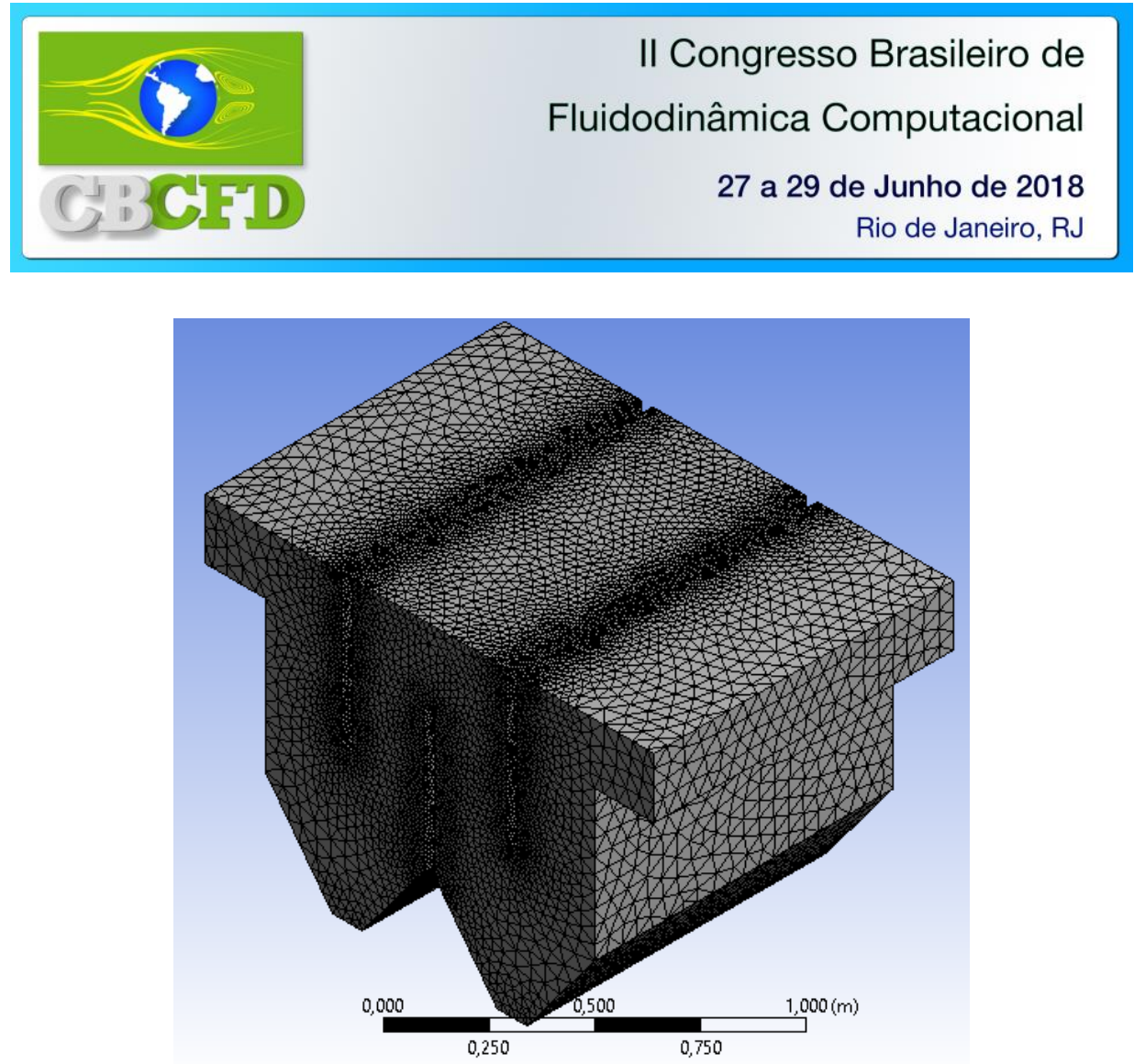

Figura 2 - Malha utilizada na simulação

O escoamento foi modelado no ANSYS Fluent, definindo as condições de entrada como ar a $10 \mathrm{~m} / \mathrm{s}$ a $25^{\circ} \mathrm{C}$ e $1 \mathrm{~atm}$, e condições das saídas (lateral e inferiores) sendo outflow, e os materiais utilizados no projeto (equipamento em aço).

Utilizou-se o modelo de turbulência $k$ - $\varepsilon$ padrão através de regime estacionário. Para a análise das zonas de velocidade no interior do equipamento foi implementado o escoamento do tipo monofásico.

\section{RESULTADOS E DISCUSSÃO}

Após as simulações, foi obtido os perfis e vetores de velocidade para a estrutura proposta, que pode ser observada, respectivamente, na Figuras 3 na Figura 4.

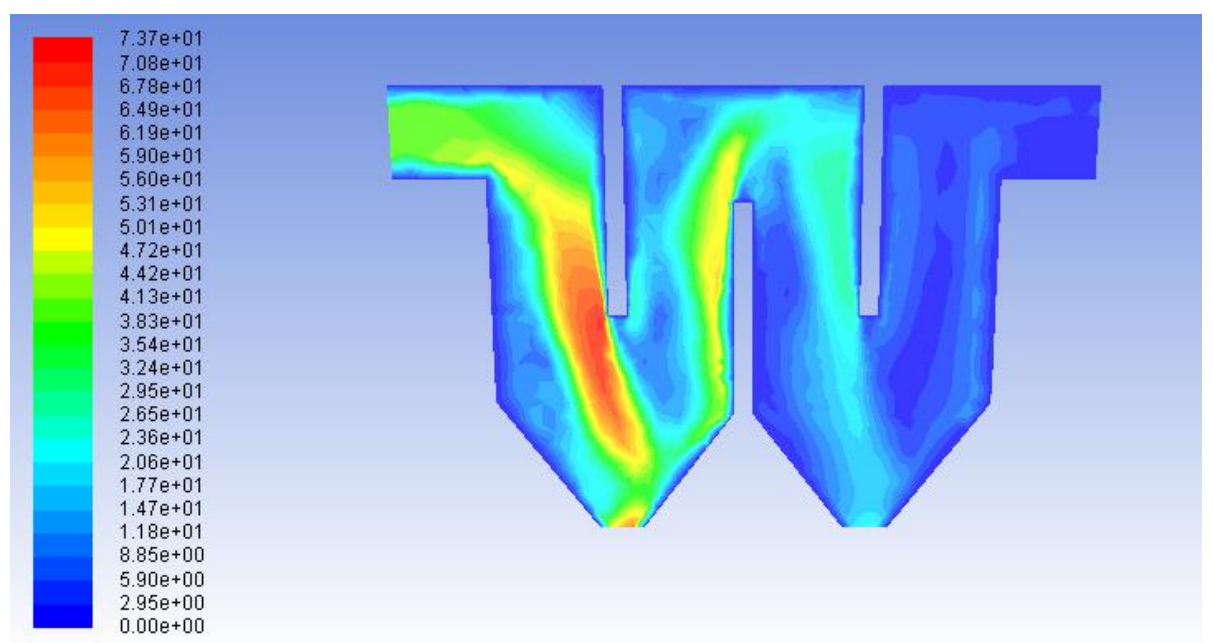

Figura 3 - Contorno do perfil de velocidade no equipamento 

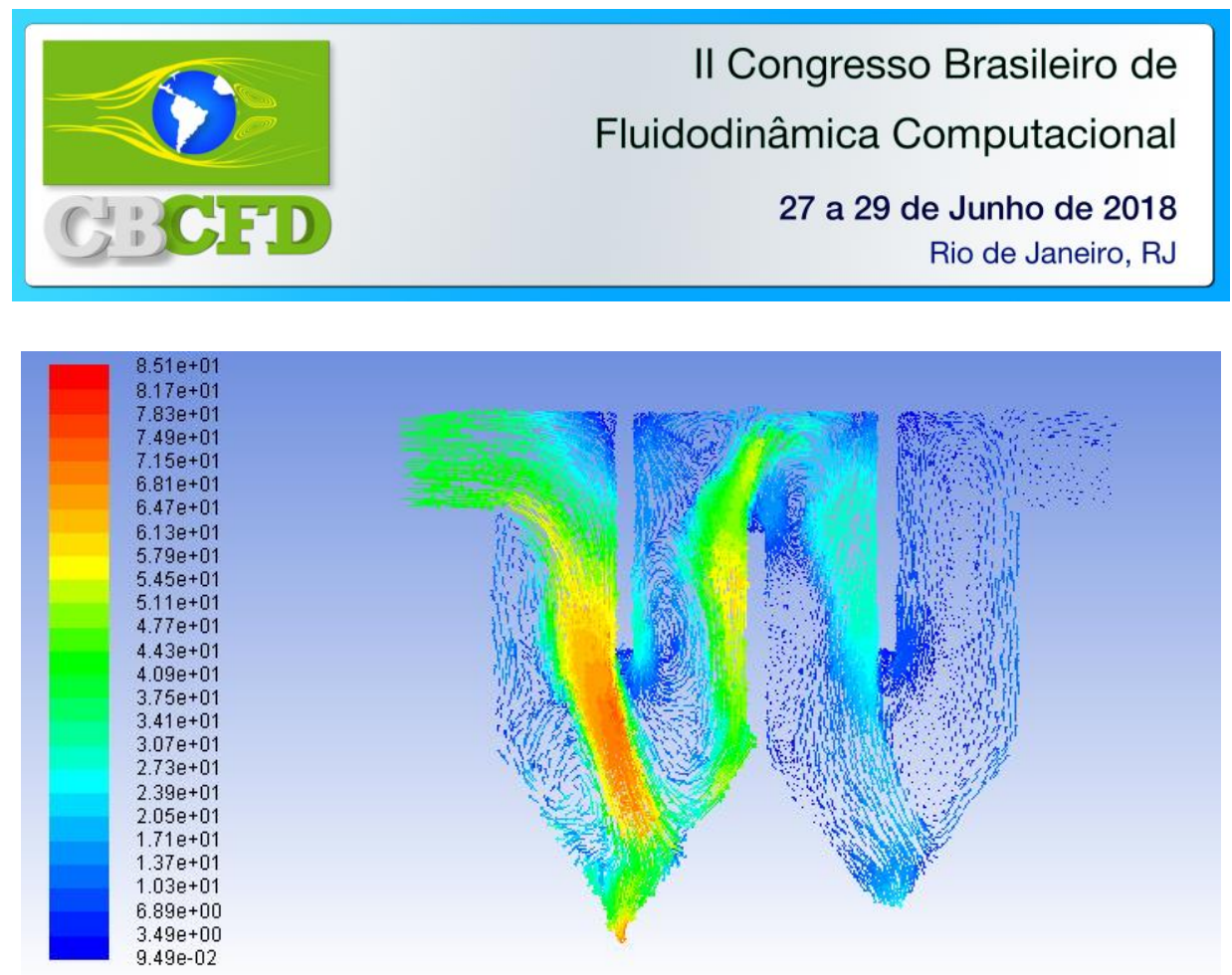

Figura 4 - Vetores de velocidade do escoamento do fluido

Com os resultados de velocidade, pode-se verificar as zonas de maior e menor velocidade no projeto. Viu-se também como o fluido passa pelo equipamento, e observou-se onde existe o maior escape de fluido (primeira saída inferior). A velocidade na segunda saída já se apresenta significantemente menor, o que não justifica a implementação de mais extensão.

\section{CONCLUSÕES}

Foi possível prever o perfil e vetores de velocidade do equipamento proposto, onde foi obtido uma maior velocidade na primeira etapa do equipamento, e uma velocidade consideravelmente baixa na segunda região do equipamento. A geometria proposta se apresentou satisfatória no fator geração de obstáculos e redução de velocidade. Esses resultados justificam a continuação do estudo com futura adição de carga na alimentação para determinar, através de simulação computacional, a quantidade de material particulado que pode ser coletado com esse equipamento instalado no topo de chaminés industriais.

\section{REFERÊNCIAS}

OMS, Organização Mundial da Saúde. Ambient Air Pollution: A global assessment of exposure and burden of disease. [S.1.: s.n.], 2016. 121 p. Disponível em: <http://www.who.int/en/>. Acesso em: 20 mai. 2017.

PAOLI, F de. Simulação em túnel de vento da dispersão de uma pluma emitida por uma chaminé isolada. 2006. Dissertação (Mestrado em Engenharia Civil) - Programa de PósGraduação em Engenharia Civil, UFRGS, Porto Alegre.

PFLUCK, C. E. de F. Simulação fluidodinâmica da dispersão de poluentes na atmosfera. 2010. 142 f. Dissertação (Mestre em Engenharia)- Programa de Pós-Graduação em Engenharia Química, Universidade Federal do Rio Grande do Sul, Porto Alegre, 2010.

THURSTON, G.D. Outdoor air pollution:sources, atmospheric transport, and human health effects. In: CAPLAN, M. Reference Module in Biomedical Sciences. [S.1.]: Elsevier, 2008. p. 700-712. 